\title{
Tako-tsubo cardiomyopathy observed in a patient with sepsis and transient hyperthyroidism
}

\section{Cardiomiopatia Tako-tsubo osservata in un paziente con sepsi e ipertiroidismo transitorio}

\author{
Filippo M. Sarullo, Luigi Americo, Salvatore Accardo, Sergio Cicero, \\ Rossella Schicchi, Maria Schirò, Antonio Castello
}

\begin{abstract}
Tako-tsubo cardiomyopathy observed in a patient with sepsis and transient hyperthyroidism. F.M. Sarullo, L. Americo, S. Accardo, S. Cicero, R. Schicchi, M. Schirò, A. Castello.

A 55 - years old woman, with a history of hypertension and ischemic stroke with residual left hemiparesis, was admitted to our hospital because of dyspnoea with clinical evidence of acute pulmonary edema. She was found to have a sinus tachycardia with ST-elevation in leads D1, aVL and V1-V4 in the electrocardiogram, and akinesis of the left ventricular apex with overall left ventricular systolic function being severely impaired and an ejection fraction of $28 \%$ on echocardiography. Orotracheal intubation was performed and mechanical ventilation was immediately started. Emergency cardiac catheterization was performed $2 \mathrm{~h}$ after the symptom onset. Coronary angiography showed no significant coronary artery
\end{abstract}

\begin{abstract}
disease. Blood analysis revealed an increase in the creatine kinase MB fraction, a significant positive detection in troponin $T$, a white blood cell count of 35000 per microliter, C-reactive protein of $59,9 \mathrm{mg} / \mathrm{dl}$, and transient elevation in the concentration of free triiodothyronine, free thyroxine, thyroid globulin antibody, and thyroid peroxidase antibody. The symptoms improved during the next days, and follow-up echocardiography 18 days later showed complete resolution of the left ventricular dysfunction.

These data suggest that tako-tsubo cardiomyopathy may be induced in patients with sepsis and transient hyperthyroidism.

Keywords: Tako-tsubo cardiomyopathy, sepsis, transient hyperthyroidism, ventricular function.
\end{abstract}

Monaldi Arch Chest Dis 2009; 72: 33-36.

Division of Cardiology, Buccheri La Ferla Fatebenefratelli Hospital, Palermo - Italy.

Corresponding author: Filippo Maria Sarullo MD; Division of Cardiology; Buccheri La Ferla Fatebenefratelli Hospital; Via Salvatore Puglisi n. 15 - I-90143 Palermo, Italy; E-mail address: E-mail: fsarullo@neomedia.it

\section{Introduction}

It is reported that myocardial depression can be demonstrated in many patients with sepsis [1-3], in which several circulating cytokines such as thumor necrosis factor alfa and interleukin-1 beta might be involved. Hyperthyroidism also can induce cardiac symptoms, arrhythmias, heart failure, and represent a cause of cardiomyopathy or ischemic heart disease in the setting of atherosclerosis or coronary artery vasospam [4]. We present au unusual case of cardiac wall motion abnormalities associated with sepsis and mild and transient hyperthyroidism.

\section{Case report}

A 55 -years old woman, with a history of hypertension and ischemic stroke with residual left hemiparesis, was admitted to our hospital because of dyspnoea with clinical evidence of acute pulmonary edema, on December 4, 2007.

On admission, her consciousness was clear. Physical examination showed a height of $160 \mathrm{~cm}$, body weight of $62 \mathrm{~kg}$, a temperature of $38.5^{\circ} \mathrm{C}$ without de- hydration state, a regular pulse of 140 beats/min, and a blood pressure of $180 / 100 \mathrm{mmHg}$. The chest radiography showed mild cardiomegaly with pulmonary congestion. The 12-lead electrocardiogram (ECG) showed sinus tachycardia and ST-segment elevation in leads I, aVL, and V1 through V4 (Figure 1), and echocardiogram showed akinesis of the left ventricular apex with overall left ventricular systolic function being severely impaired with an ejection fraction of 28\% (Figure 2).

Arterial blood gas (ABS) showed a $\mathrm{pH}=7.068$, an arterial oxygen pressure $=62 \mathrm{mmHg}$, an arterial carbon dioxide pressure $=53 \mathrm{mmHg}$, an oxygen saturation $=82 \%$, a lactate concentration $=3,8$ $\mathrm{mmol} / \mathrm{L}$, and a $\mathrm{cHCO} 3=-12.8 \mathrm{mmol} / \mathrm{L}$.

Orotracheal intubation was performed and mechanical ventilation was immediately started. Because of the clinical picture consistent with apical acute myocardial infarction the patient was brought to the Cardiac Catheterization Laboratory, two hours after the symptom onset, to undergo coronary angiogram and primary angioplasty. However, coronary angiogram showed completely normal coronary vessels, without atherosclerotic lesions or intravascular thrombosis. 


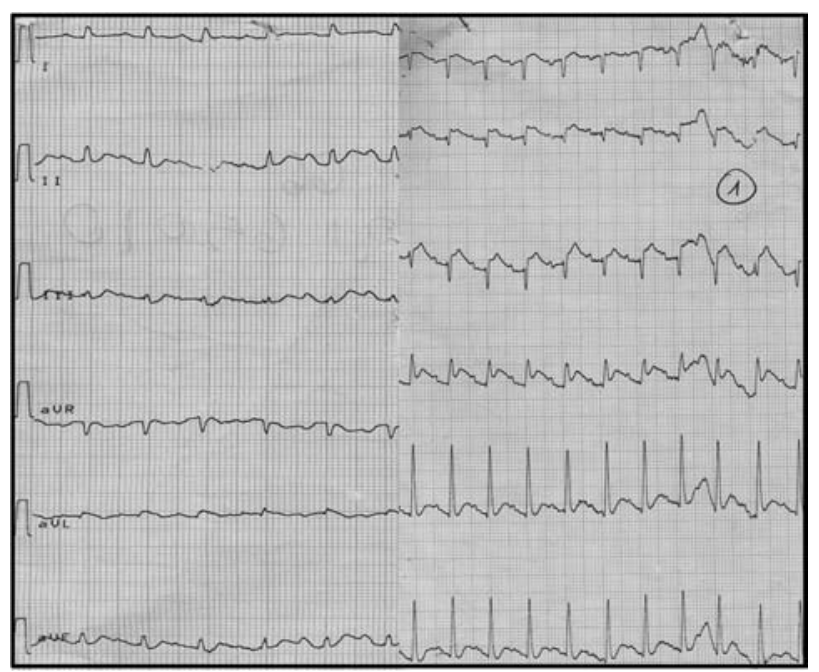

Figure 1. - The 12-lead electrocardiogram showed sinus tachycardia and ST-segment elevation in leads I, aVL, and V1 through V4.

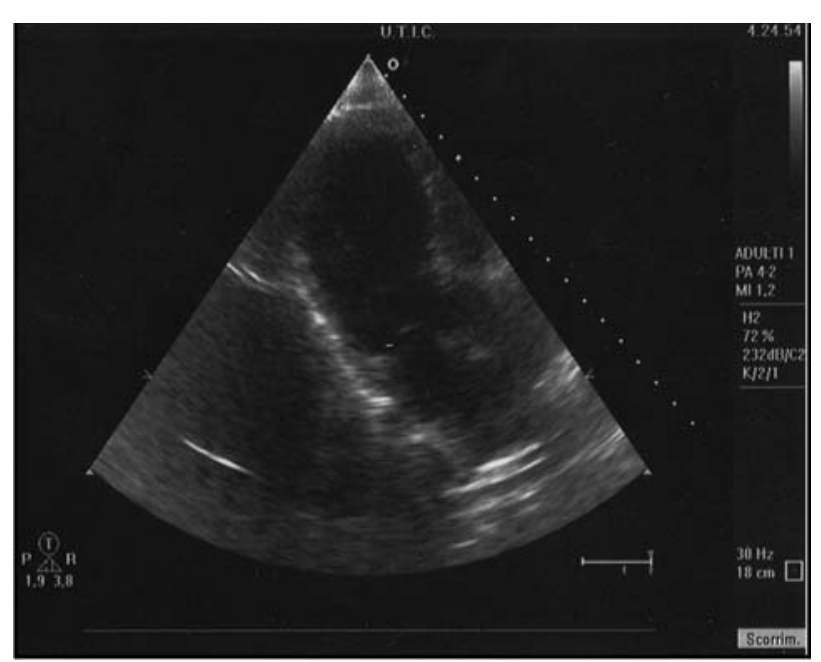

Figure 2. - Echocardiogram showed akinesis of the left ventricular apex with overall left ventricular systolic function being severely impaired (EFVS: 28\%).

Blood analysis revealed an increase in the creatine kinase $\mathrm{MB}$ fraction (plasma peak was 75,98 $\mathrm{ng} / \mathrm{ml}$ ), a significant positive detection in troponin $\mathrm{T}$ (plasma peak was 2,850 ng/ml), a white blood cell count of 35540 per microliter with $87,5 \%$ of neutrophilis, C -reactive protein of $59,9 \mathrm{mg} / \mathrm{dl}$. The results of thyroid function test were as follows: thyroid stimulating hormone (TSH): $0,005 \mathrm{uU} / \mathrm{ml}$ (normal range, 0,270 - 4,200), free triiodothyronine (fT3): 7,44 pg/ml (normal range, 2,00 - 4,40), free thyroxine (fT4): $3,28 \mathrm{ng} / \mathrm{ml}$ (normal range, 0,93 1,70), thyroid globulin antibody: $3000 \mathrm{UI} / \mathrm{ml}$ (normal range, $<40)$, thyroid peroxidase antibody: 1000 $\mathrm{UI} / \mathrm{ml}$ (normal range, $<35$ ), TSH receptor antibody: $69.5 \%$ (normal range, $<15,0$ ).

After the achieved of stable hemodynamic conditions, the patient was transferred to our Cardiology Division, to correctly define the etiology of electrocardiografic and echocardiographic alterations.

Based on the findings, we diagnosed Tako-tsubo cardiomyopaty associated with sepsis and hyperthyroidism. Staphylococcus cohnii ssp cohnii was detected in cultures from both blood and urine. Although tests to confirm a diagnosis of acute myocarditis was also performed (identification of the virus in stool, throat washings, blood, or by a distinct increase in virus-neutralizing antibody, complementfixation, or hemagglutination inhibition titers, and cardiac biopsies on the seventeenth day), there was no evidence of acute myocarditis. The patient never experienced further symptoms after treatment with levofloxacin (500 mg b.i.d), prednisone (12.5 mg once a day), propranolol (20 mg t.i.d.), ramipril (10 mg once a day), tiamazol (5 $\mathrm{mg}$ b.i.d), amlodipine (5 $\mathrm{mg}$ once a day), and cardioaspirin (100 mg once a day).

The electrocardiography revealed normalization of the elevated ST segment and inversion of T wave in leads D1, D2, aVL, and V2 through V6 on the twenty-third day (Figure 3). The echocardiogram 18 days after hospitalization showed completely normal left ventricular kinesis, with complete regression of apical dilation and akinesis previously evidenced (Figure 4). The thyroid function gradually recovered, as so as improvement of infection (white blood cell was normalized when she was discharged). Six months later, she was in euthyroid state and free from symptoms.

\section{Discussion}

"Tako tsubo cardiomyopathy" or transient left ventricular apical ballooning is a recently identified syndrome whose clinical presentation is similar to that of acute myocardial infarction (AMI) with acute

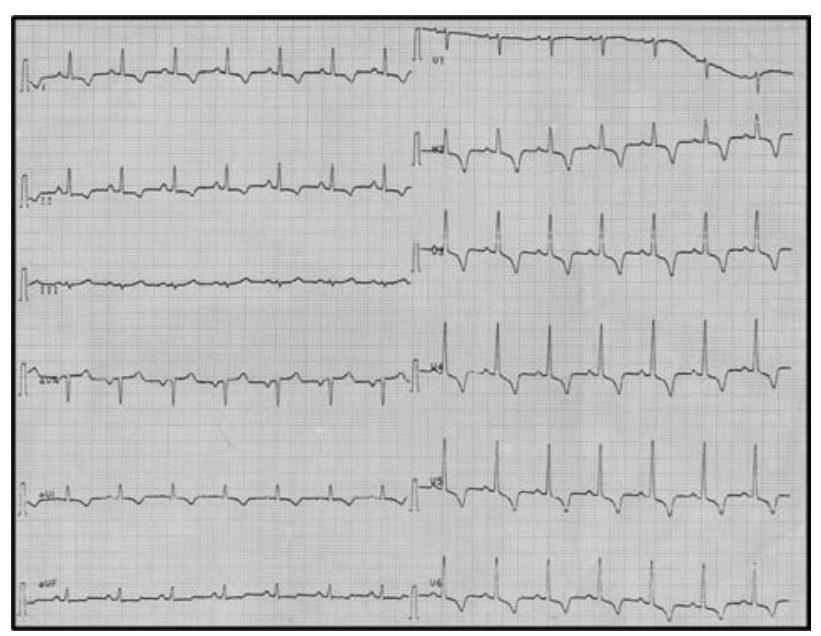

Figure 3. - The 12-lead electrocardiogram showed normalization of the ST-segment elevation and inversion of T wave in leads I, II, aVL, and V2 through V6.

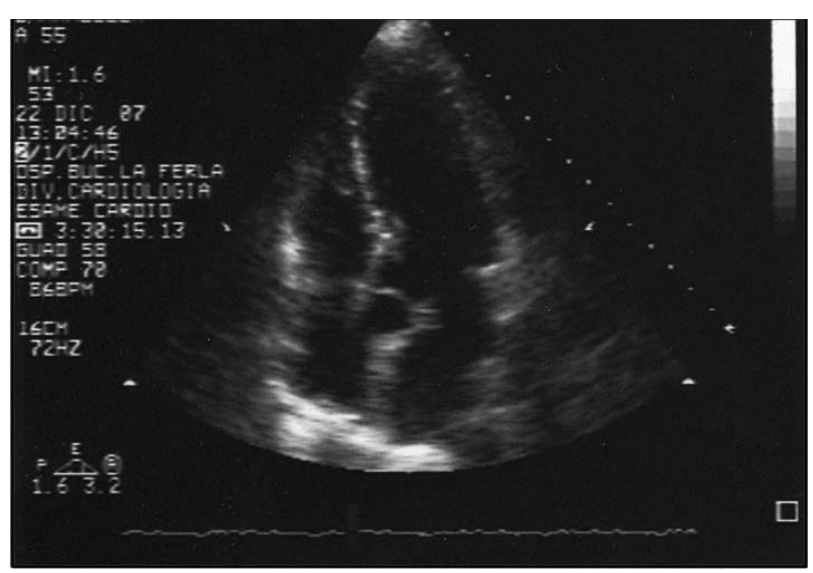

Figure 4. - Echocardiogram showed completely normal left ventricular kinesis after 18 days. 
kinetic alteration that involve the left ventricular apex and gives a shape which is very similar to a fishing pot (tako-tsubo) used by Japanese fishermen to catch octopus $[5,6]$. Transient left ventricular apical ballooning typically affects women, and the clinical presentation is comparable to acute coronary syndrome with chest pain or sudden dyspnoea, changes in ECG and elevated cardiac enzymes in the absence of significant coronary stenosis, with complete resolution of wall-motion abnormalities in a period of day or weeks.

The precise etiology of Tako tsubo cardiomyopathy is still obscure, although its onset is typically triggered by acute medical illness or intense emotional or physical stress [7, 8]. Several mechanism have been proposed that may result in transient left ventricular apical ballooning, including multivessel epicardial spasm [5], coronary microvascular dysfunction [9], and catecholaminemediated neurogenic stunning [10]. It was reported that myocardial depression can be demonstrated in many patients with sepsis $[1,2]$, in which several circulating cytokines such as thumor necrosis factor alfa and interleukin-1 beta might be involved. Myocardial depression secondary to sepsis presents with biventricular dilation and depression of the ejection fraction $[1,2]$. In the present case, echocardiography revealed no biventricular dilation, but it did show apical dyskinesis, as well as depression of the ejection fraction. Tako tsubo cardiomyopathy may coexist in the condition, which is known as myocardial depression during sepsis. On other hand, there are several reports of patients with normal coronaries and with angina and hyperthyroidism, similar to our patient. Angiographically, vasospam can be identified in patients with hyperthyroidism [11-15]. Masani et al. [11], described a case of myocardial infarction due to vasospam with hyperthyroidism and reported that vasospam disappeard after the patient had been rendered euthyroid. Featherstone and Stewart [12] also reported that a patient with hyperthyroid Graves' disease had vasospastic angina. They demonstrated that in a hypothyroid state with iodine 131 therapy the patient became free of angina, while the patient's angina returned in the hyperthyroid stage by increasing levothyroxine sodium. Moliterno and al. [13], reported a case in which the repetitive occurrence of episodes of myocardial ischemia due to coronary spam was correlated with repeated transient elevations in thyroid hormone levels. Severe reversible ischemia due to excess thyroid administration has been reported [14]. Vasospam was also angiographically identified in a patient with occult hyperthyroidism [15]. Thus, spastic angina may be induced in patient with both transient or persistent hyperthyroidism. Our patient took amlodipine $5 \mathrm{mg}$ per day, and we did not attempt to provoke vasospam during coronary angiography. Furthermore, the addition of $60 \mathrm{mg}$ of propranolol did not induce chest pain or ECG changes. However, we cannot exclude the possibility of coronary vasospam associated with transient hyperthyroidism in the acute phase. Furthermore, we cannot rule out the possibility of thromboembolus, which had resolved during the acute phase. Finally, the increases in the thyroid hormone concentrations might directly influence the myocardium, although we cannot explain why the wall motion abnormalities were present only in the apex. Generally, hyperthyroid patients are in a high output state in the absence of symptomatic heart failure because of a lower systemic vascular resistance and increased sodium reabsorption and blood volume. However, in a small subset of patients with persistent sinus tachycardia or atrial fibrillation, low output heart failure (hyperthyroid cardiomyopathy) can develop and is reversible when euthyroid state is re-established [4, 16-18]. Several investigations have reported that thyroid hormone interacts with catecholamines such that hyperthyroid patients have an increased sensitivity to catecholamine action [19-20].

In conclusion, we presented an unusual case of Tako Tsubo cardiomyopathy associated with sepsis and transient hyperthyroidism. Sepsis and hyperthyroidism should be considered as a possible cause of cardiac wall motion abnormalities.

\section{Riassunto}

Riportiamo il caso di una donna di 55 anni affetta da ipertensione arteriosa e da esiti di pregresso insulto ischemico cerebrale, che giungeva alla nostra osservazione in edema polmonare acuto. L'ECG di superficie registrato all'ingresso in area di emergenza mostrava una tachicardia sinusale con sopraslivellamento del tratto ST in sede antero-laterale e l'ecocardiogramma una severa acinesia dell'apice del ventricolo sinistro con severa riduzione della funzione di pompa (FEVS: 28\%). Per la concomitante presenza di severa acidosi metabolica all'emogasanalisi, la paziente veniva sottoposta ad intubazione oro-tracheale e trasferita in sala di emodinamica entro due ore dall'insorgenza dei sintomi, per essere sottoposta ad esame coronarografico in previsione di una procedura di rivascolarizzazione meccanica. La coronarografia non mostrava una significativa patologia aterosclerotica, tuttavia si registrava un movimento tipico degli enzimi cardiaci espressivi di necrosi miocardica. Inoltre si evidenziava una marcata leucocitosi neutrofila $(35.000$ G.B. per microlitro), un marcato incremento della PCR $(59,9 \mathrm{mg} / \mathrm{dl})$ ed un transitorio incremento degli ormoni tiroidei (fT3, fT4) degli anticorpi anti-tireoglobulina e della anti-tireoperossidasi.

Nei giorni successivi le condizioni cliniche della paziente miglioravano e l'ecocardiogramma, eseguito in diciottesima giornata dall'evento acuto, mostrava un completo recupero della cinesi segmentaria in regione apicale e la normalizzazione della funzione di pompa del ventricolo sinistro.

I dati clinici strumentali e l'evoluzione clinica suggerivano la diagnosi di Cardiomiopatia di Takotsubo associata a sepsi e transitorio ipertiroidismo.

\section{References}

1. Court O, Kumar A, Parrillo JE, et al. Clinical review; myocardial depression in sepsis and septic shock. Crit Care 2002; 6: 500-508.

2. Ohigashi-Suzuki S, Saito Y, Tatsuno I. Tako tsubo cardiomyopathy associated with sepsis in type 2 diabetes mellitus. Am J Emerg Med 2007; 25(2): 230-232. 
3. Grocott-Mason RM, Shah AM. Cardiac dysfunction in sepsis: new theories and clinical implications. Intensive Care Med 1998; 24: 286-295.

4. Klein I, Ojamaa K. Thyroid hormone and cardiovascular system. N Engl J Med 2001; 344: 501-509.

5. Dote K, Sato H, Tateishi H, Uchida T, Ishihara M. Myocardial stunning due to simultaneous multivessel coronary spasms: a review of 5 cases. J Cardiol 1991; 21: 203-214.

6. Kawai S, Suzuki H, Yamaguchi H, et al. Ampulla cardiomyopathy ("tako tsubo" cardiomyopathy): reversible left ventricular dysfunction wiith ST-segment elevation. Jpn Circ J 2000; 64: 156-159.

7. Sharkey SW, Lesser JR, Zenovich AG, et al. Acute and reversible cardiomyopathy provoked by stress in women from the United States. Circulation 2005; 111: 472-479.

8. Wittstein IS, Thiemann DR, Lima JA, et al. Neurohumoral features of myocardial stunning due to sudden emotional stress. N Engl J Med 2005; 352: 539-548.

9. Kurisu S, Inoue I, Kawagoe T, et al. Left ventricular apical thrombus formation in a patient with suspected tako-tsubolike left ventricular dysfunction. Circ J 2003; 67: 556-558.

10. Akashi YJ, Nakazawa K, Sakakibara M, et al. Reversible left ventricular dysfunction "takotsubo" cardiomyopathy related to catecholamine cardiotoxicity. $J$ Electrocardiol 2002; 35: 351-356.

11. Masani ND, Northridge DB, Hall RJ. Severe coronary vasospam associated with hyperthyroidism causing myocardial infarction. Br Heart J 1995; 74: 700-701.
12. Featherstone HJ, Steward DK. Angina in thyrotoxicosis. Thyroid-related coronary artery spam. Arch Intern Med 1983; 143: 554-555.

13. Moliterno D, DeBold CR, Robertson RM. Case report: coronary vasospam-relation to the hyperthyroid state. Am J Med Sci 1992; 304: 38-42.

14. Bergeron GA, Goldsmith R, Shiller NB. Myocardial infarction, severe reversible ischemia, and shock following excess thyroid administration in a woman with normal coronary arteries. Arch Intern Med 1988; 148: 1450-1453.

15. Wei JY, Genecin A, Greene HL, Achuff SC. Coronary vasospam with ventricular fibrillation during thyrotoxicosis: response to attaining euthyroid state. Am J Cardiol 1979; 43: 335-339.

16. Fadel BM, Ellahham S, Ringel MD, Lindsay J Jr, Wartofsky L, Burman KD. Hyperthyroid heart disease. Clin Cardiol 2000; 23: 402-408.

17. Kantharia BK, Richards HB, Battaglia J. Reversibile dilated cardiomyopathy: an unusual case of thyrotoxicosis. Am Heart J 1995; 129: 1030-1032.

18. Sasaki T, Fujioka Y, Akagami T, et al. Cardiac wall motion abnormalities observed in a patient with transient hyperthyroidism. Jpn Heart J 2004; 45: 1071-1077.

19. Levey GS. Catecholamine sensitivity, thyroid hormone and the heart: a reevaluation. Am J Med 1971; 50: 414-420.

20. Polikar R, Burger AG, Sherrer U, Nicod P. The thyroid and the heart. Circulation 1993; 87: 1435-1441. 